\title{
Plasma-Detonation Technology for Modification of the Surface Layer of Metal Parts
}

\author{
Yu N. Tyurin* and O.V. Kolisnichenko \\ E.O. Paton Electric Welding Institute NASU. 11, Bozhenko Str., Kiev-5, 03680, Ukraine
}

\begin{abstract}
Structuring of surfaces of metal parts is performed with the electric current commutated by the pulsed plasma. Alloying elements are added to plasma and participate in a micro metallurgical process occurring on the molten surface of a part. Heat capacity of metal of the part provides the high rates of cooling and solidification of the melt. Cycling of the melting and solidification process under conditions of pulsed physical fields provides stirring and crystallisation of alloy to form microcrystalline structures. The technology is implemented using ingenious accelerators of alloying elements, which are based on development of the non-stationary processes of detonation of combustible gas mixtures in the electric field. The surface is treated with the pulsed, electric, magnetic, acoustic and elastic-deformation fields, thus enhancing the "abnormal" heat and mass transfer processes and providing formation of new materials and alloys with microcrystalline structures in surface layer.
\end{abstract}

\section{INTRODUCTION}

Performance of metal parts often depends upon the quality characteristics of the surface layer. Different technologies are applied to change phase composition and structure of this layer, including, for example, elasto-plastic deformation [1], and treatment of the surface using different types of pulsed plasmatrons [2-4], and hardening of the surface using electro-acoustic sputtering [5], and using different types of laser devices for treatment of the surface [6-7].

Electric energy is used in the majority of the pulsed plasma devices, and they differ only in design characteristics, e.g. electric-discharge compressor [4] and electromagnetic accelerator [2], whereas devices using the kinetic energy of a metal piston have fundamental differences [3]. Adiabatic compression of gas in such a device imparts it a corresponding temperature and pressure. Pulsed plasma based on nitrogen and products of erosion of the device components is used in the majority of cases for alloying the surfaces of work pieces.

We developed the plasma-detonation technology for modification of the surface layer of metal parts with alloying elements on the basis of analysis of physical-chemical phenomena occurring under the pulsed electric, magnetic, acoustic, mechanical, thermal and chemical effects [8-9]. For this purpose, we developed corresponding devices using the principle of pumping the products of detonation combustion of fuel gas mixtures with the electric energy [9-10].

Distinctive feature of such a plasma-detonation device is the possibility of switching the electric current by the ionized gas region at the detonation wave front. This makes it possible to generate the pulsed plasma at a frequency of $1-10 \mathrm{~Hz}$ and energy of $15 \mathrm{~kJ}$. Other peculiarities of our device include also the possibility of adding different alloying elements

*Address correspondence to this author at the E.O. Paton Electric Welding Institute NASU. 11, Bozhenko Str., Kiev-5, 03680, Ukraine;

E-mail: ytyurin@i.com.ua
(C, N, W, Mo, Cr, Ti, V, Al, etc.) into the plasma, which creates conditions for the chemical impact on the surface, plasma-chemical synthesis and formation of materials containing intermetallic structures in the surface layer.

When the pulsed plasma jet is emitted from the device, it switches the electric energy between the special electrode anode and surface of a work piece - cathode. This results in formation of the magnetic field with intensity up to $4 \cdot 10^{5}$ $\mathrm{Am}^{-1}$ and makes it possible to control the thermal power density of the plasma in a range of $10^{3}-10^{7} \mathrm{~W} \mathrm{~cm}^{-2}$. The high-velocity plasma jet provides acoustic and mechanical impact on the workpiece surface. Addition of discrete metallic materials to the jet provides formation of the surface layer and its alloying with the plasma components.

The investigations conducted and experience of commercial application of plasma-detonation devices proved their high efficiency in technologies used for alloying and structuring of the surface layer on parts made from iron-base alloys with a carbon content of 0.4-1.0\% [10-13].

\section{EXPERIMENTAL}

The E.O. Paton Electric Welding Institute of the NAS of Ukraine developed the plasma-detonation device (PDD) to generate high-energy plasma pulses, which can contain sets of different alloying elements (Fig. 1) [9].

When using this device, the detonation wave (DW) propagates between two coaxial electrodes (Fig. 1). In the presence of external electric field the electric current flows over the gas layer behind the detonation wave, and an additional inflow of gas is formed due to Joule dissipation. Schematic of PDD shows reaction chamber 1, consumable electrode 2, detonation device 3 and high-voltage power source 4 . The intensity of the electric field varies along length of the reaction chamber.

To calculate the PDD parameters, we added to the following formula the geometric and energy parameters averaged in width of the inter-electrode gap: 
$\langle X\rangle=\frac{1}{s} \int_{0}^{s} X d s$,

where $X$ takes the values of current density, plasma flow velocity, magnetic and electric field intensity, etc; and $s$ is the width of the annular inter-electrode gap. Solution and examples of calculation of the PDD parameters are given in [9].

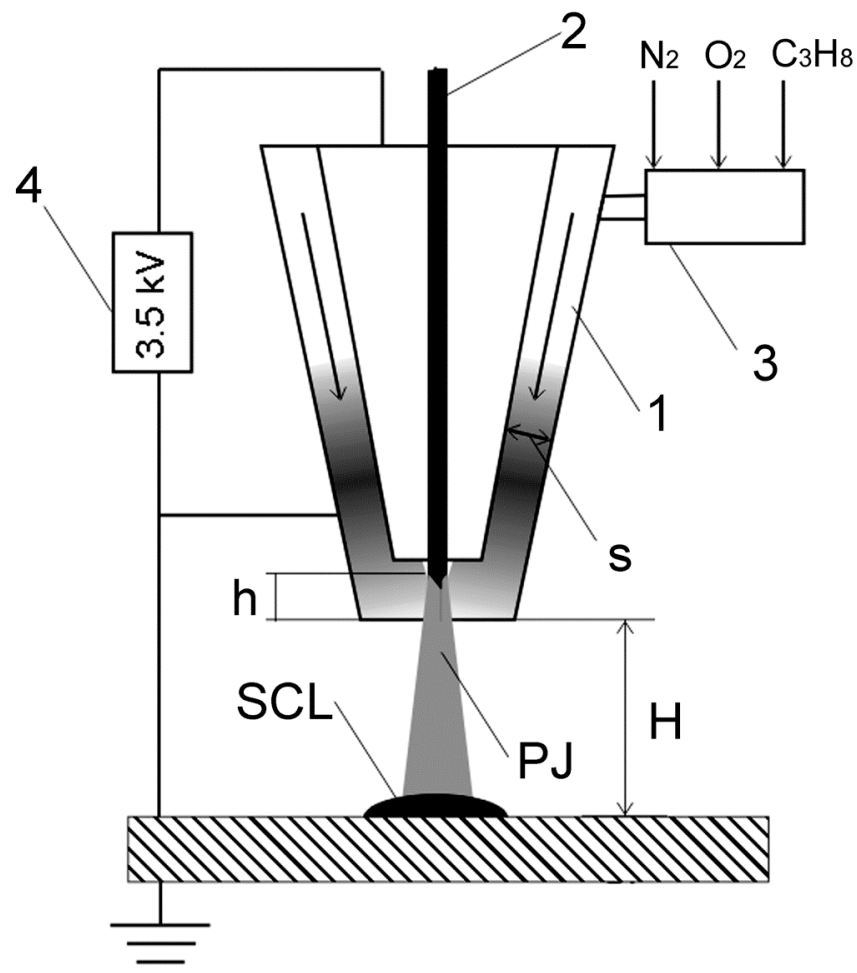

Fig. (1). The scheme of the detonation device with an electromagnetic principle of input of additional energy.

Results of numerical integration of the conventional differential equation under preset initial conditions show that the second factor, i.e. supply of Joule heat, is involved into acceleration of DW with increase in electric field intensity. In this case, acceleration of DW is accompanied by growth of temperature, which in turn leads to increase in velocity and density of the plasma flow. The temperature, velocity and density of the pulsed plasma jet in the reaction chamber can be varied depending upon the length, taper angle and size of the gap between the electrodes.

After DW goes out from the channel, the electric current starts flowing from the anode to the melted surface (cathode) through the plasma jet (PJ) (Fig. 1), behind the exit section of the PDD nozzle. This results in an additional release of energy in the layer of the shock-compressed plasma flowing onto the work piece surface.

As shown by analysis, conductivity of this layer is two orders of magnitude lower than that of the plasma jet, which makes it possible to maintain in it a high intensity of the electric field, up to $(0.5-1.0) \cdot 10^{6} \mathrm{~V} \mathrm{~m}^{-1}$, and provide a high voltage drop.

The high-energy gas jet, while following onto the work piece surface, forms a shock-compressed layer (SCL) (Fig.
1). The electric current flows through the plasma jet almost without any losses to SCL, where it is transformed into heat.

Energy characteristics of the plasma jet at its exit from the plasma-detonation device depend upon the dimensions of the chamber, where acceleration and heating of gas take place, as well as upon the intensity of the electric field. At a length of the inter-electrode gap equal to $200 \mathrm{~mm}$ and intensity of the electric field equal to $400-500 \mathrm{kV} \mathrm{m}^{-1}$, the plasma jet has a temperature of $20000 \mathrm{~K}$ and velocity of $6 \mathrm{~km} / \mathrm{s}$. Increase in length of the inter-electrode gap increases the velocity and temperature of the plasma jet [9-10].

Flowing from the device, plasma provides switching of the electric current between the work piece surface being modified and special electrode. The amplitude value of the switched current is 1-4 kA, and depends upon distance $\mathrm{H}$ from the electrode to the workpiece surface and size of a recess, $\mathrm{h}$, at the electrode tip to the exit section of the device nozzle for generation of plasma (Fig. 2).

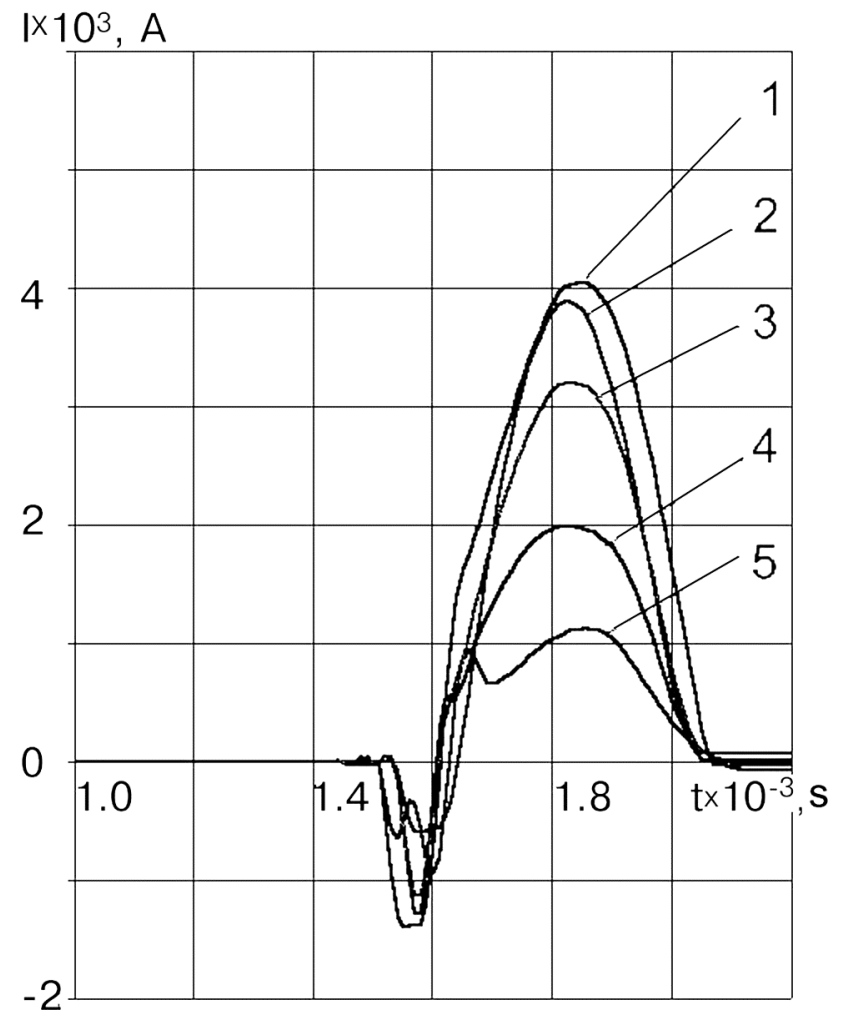

Fig. (2). Variations of current in plasma interacting with workpiece surface: $1-\mathrm{h}=20 \mathrm{~mm}, \mathrm{H}=40 \mathrm{~mm} ; 2-\mathrm{h}=0 \mathrm{~mm} \mathrm{H}=70 \mathrm{~mm} ; 3-$ $\mathrm{h}=20 \mathrm{~mm}, \mathrm{H}=70 \mathrm{~mm} ; 4-\mathrm{h}=40 \mathrm{~mm} \mathrm{H}=70 \mathrm{~mm} ; 5-\mathrm{h}=20 \mathrm{~mm}$, $\mathrm{H}=100 \mathrm{~mm}$.

The high-velocity plasma jet, consisting of a set of alloying elements in the form of ions and overheated vapours, flows onto the work piece surface to form a layer of the shock-compressed gaseous material having an increased pressure (Fig. 3).

Electric conductivity of this shock-compressed layer depends upon its thickness, intensity of the field, and temperature of heating of the work piece surface. Thermo emission of electrons from heated regions of the metal surface serves as a catalyst for discharges of the electric current with diffusion fixation to the gas boundary of the shock-compressed 
layer. As a result, the work piece surface is subjected to a local effect by many electric discharges developing in the shock-compressed layer (Fig. 3). Charging of the shockcompressed layer with energy is provided due to the electric potential $(3.5 \mathrm{kV})$ between the anode in the plasmadetonation device and surface of a solid body - cathode. As shown by the investigations, the plasma jet switches the electric current between the anode and workpiece surface, having a density of up to $7000 \mathrm{~A} \mathrm{~cm}^{-2}$ and duration of the effect equal to $0.5 \mathrm{~ms}$ (Fig. 2).

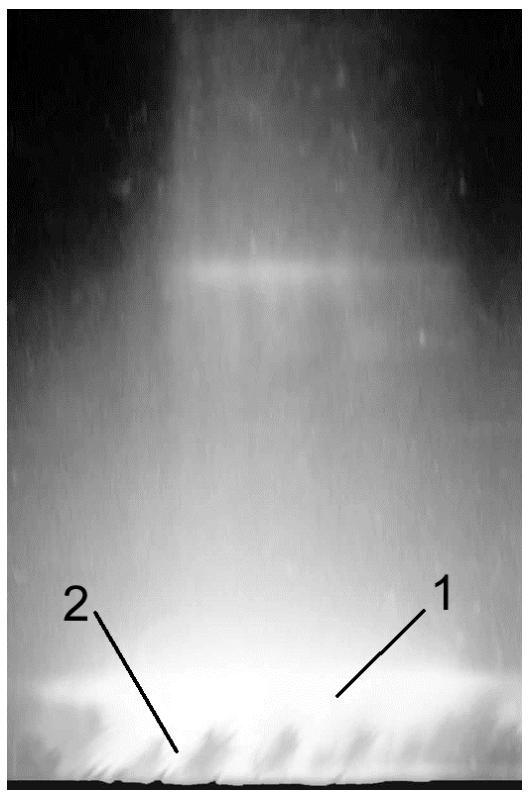

Fig. (3). Shock-compressed layer -1 and electric discharges -2 in this layer.

Result of the electric current flow is formation of a pulsed magnetic field of up to 3000 Oe. The magnetic field causes increase in thermal conductivity, formation of internal electric currents in the treated layer of a metal workpiece, and changes in its properties.

Thermal effect on the surface treated is realised as a rule due to heat transfer from a heat carrier. The heat carrier is a shock-compressed layer of gas on the surface of a solid body. The high energy density provides high temperature gradients, both in heating and in cooling of the work piece surface layer (Fig. 4). Heating of the work piece surface is realised also due to other types of effects: acoustic, mechanical, and electromagnetic and beam.

The cyclic thermal effect with a frequency of $3-5 \mathrm{~Hz}$ causes periodic heating of the surface up to a melting point, which changes the phase state of the metal layer and accelerates transfer of alloying elements. Multiple heating and cooling of the surface layer with high temperature gradients (Fig. 4) lead to periodic changes in stresses and strains in this layer, which causes substantial changes in the structural state of a metal alloy.

Plasma-detonation treatment is accompanied by a pulsed mechanical pressure of the high-velocity plasma jet, which is decelerated on the surface. The energy (up to $4 \mathrm{~kJ}$ ) of free gas-dynamic shocks is determined by mass and velocity of the plasma jet.
Mechanical effect is considered to be an efficient means of acceleration of chemical and mass-exchange processes occurring in a solid body. It activates oscillation processes in a metal alloy, excites long-wave acoustic phonons, thus accelerating cooling and crystallisation, and intensifies masstransfer of alloying elements in the heated layer.
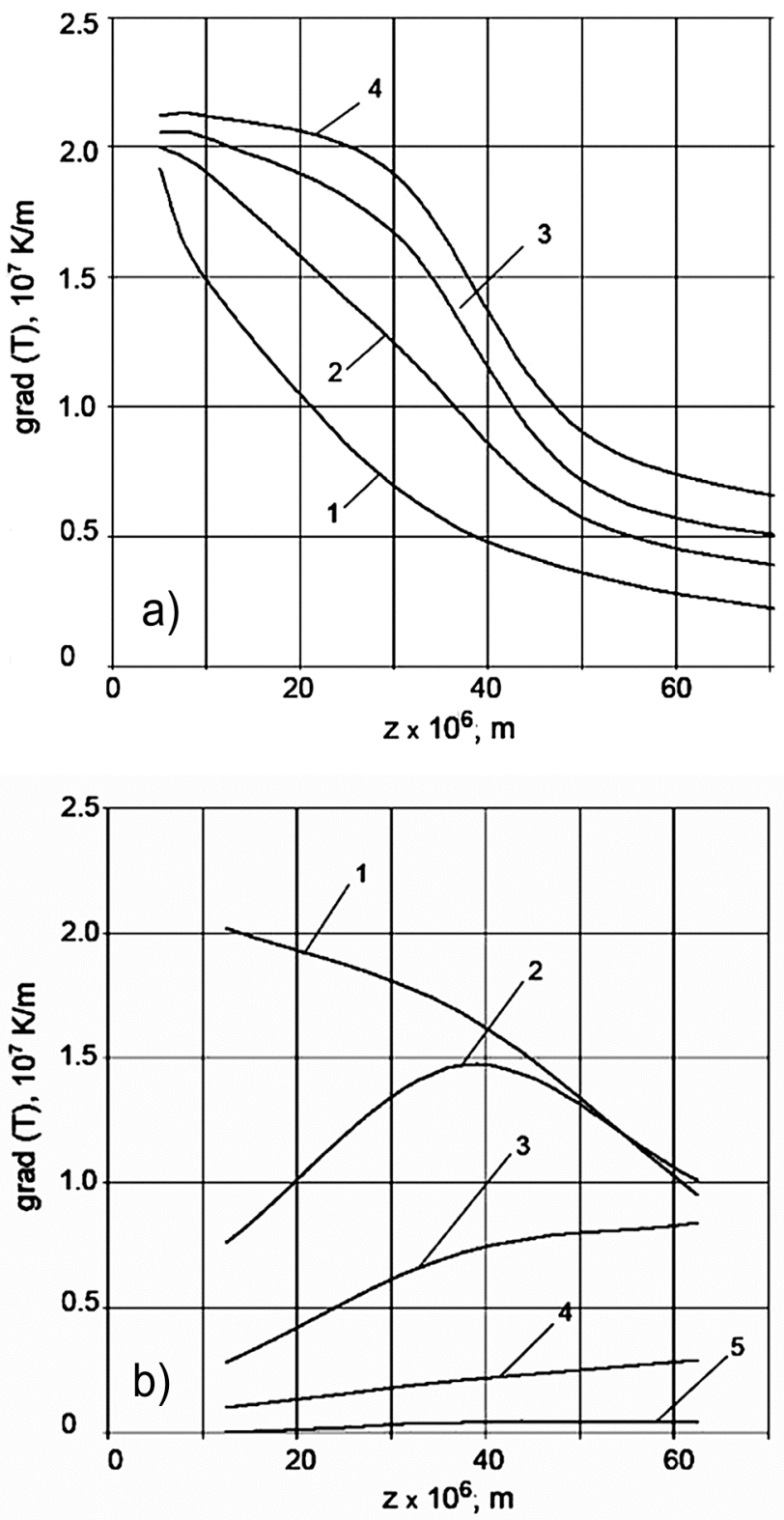

Fig. (4). Variations of temperature gradients in heating and cooling of the surface layer for the time of the effect: $1=0 \mathrm{~s}, 2-10 \mathrm{~ms} ; 3-$ $20 \mathrm{~ms} ; 4-30 \mathrm{~ms} ; 5$ - $40 \mathrm{~ms}$. (a) - heating; (b) cooling.

The high-velocity plasma jet is accompanied by a powerful sound wave (up to $150 \mathrm{~dB}$ ) [9-10]. Acoustic oscillations have a sonic frequency $\left(20-20 \cdot 10^{3} \mathrm{~Hz}\right)$. The acoustic effect is a propagation of elastic or quasi-elastic oscillations in a treated medium. Acoustic waves intensify chemical transformations (sonolysis) and raise efficiency of the mechanical, thermal and chemical effects.

Plasma containing the vapours of metals (W, Mo, Cr, Cu, $\mathrm{Fe}$ ) overheated to a temperature of $15000-20000 \mathrm{~K}$ is known to form an intensive infrared and ultraviolet radiations. The 
long-wave radiation provides extra heating of the surface and alloying elements, whereas the short-wave radiation intensifies photochemical reactions in the shock-compressed layer and on the work piece surface. Intensification of physicalchemical transformations under the pulsed energy effects is provided by using the principles of concentration selectivity, which suggests that it is necessary to have a concentration of the energy effect on the work piece surface in the right place and in the right time.

Chemical effect on the surface is realised due to an addition to plasma of the materials that initiate or accelerate chemical reactions (catalysts) and enter into chemical interaction with a metal alloy on the work piece surface. The device we offer allows a combination of chemical materials, differing in mass and composition, which may be active both with respect to work piece surface and to each other, to be added to the plasma jet.

\section{STRUCTURING OF THE SURFACE LAYER}

In plasma-detonation treatment, the layer on the work piece surface is subjected to deformation two times. In heating the maximal deformation stresses are formed at the end of a heating pulse, and in cooling they are formed at the beginning (Fig. 4).

Transverse shear of the material in surface layers of a solid body was calculated using the results of experimental studies. The values of shear stresses in a layer are much higher than the values of tensile strength of metal due to temperature gradients.

Given that the treatment is performed at a pulse frequency of 3-5 Hz, the heating and cooling processes come to the end during a pause between the pulses. Accordingly, the processes of deformation and structuring of the surface layer also come to the end. This treatment causes changes in structure of the surface layer on a metal work piece, which depend upon the quantity of the affecting pulses. For example, after 5 pulses of the plasma-detonation treatment of a martensitic steel work piece the crystals in the surface layer are less than $1 \mu \mathrm{m}$ in size, and after 10 pulses they are less than $0.600 \mu \mathrm{m}$ in size (Fig. 5).

Appropriate analysis of combinations of the base and secondary energy effects allowed selecting optimal parameters for plasma-detonation treatment of the surfaces of metal parts. As a result of such a treatment the sub-microcrystalline alloyed layer is formed on the surface of martensitic steel. Composition of this layer depends upon the amount of alloying elements in plasma and quantity of treatment pulses. The most uniform and hard layer have thickness of up to $40 \mu \mathrm{m}$ after multiple (3-8 pulses) treatment (Fig. 6) [11]. The highest hardness of the treated layer equal to $16 \mathrm{GPa}$ was achieved after 8 treatment pulses and after adding metallic alloying elements, such as tungsten and molybdenum, to the nitrogen-containing plasma (Fig. 6) (specimens of steel U8 (C $-0.8 \%$ ) previously subjected to quenching and tempering). In this case the treatment was performed without melting of the surface, and specific power of the plasma jet was $10^{5} \mathrm{~W} \mathrm{~cm}^{-2}$. Microhardness was measured on transverse sections using hardness meter PMT-3. The Knoop diamond pyramid was used for the measurements. Load on the pyramid was $\mathrm{P}=0.1 \mathrm{~N}[11]$.
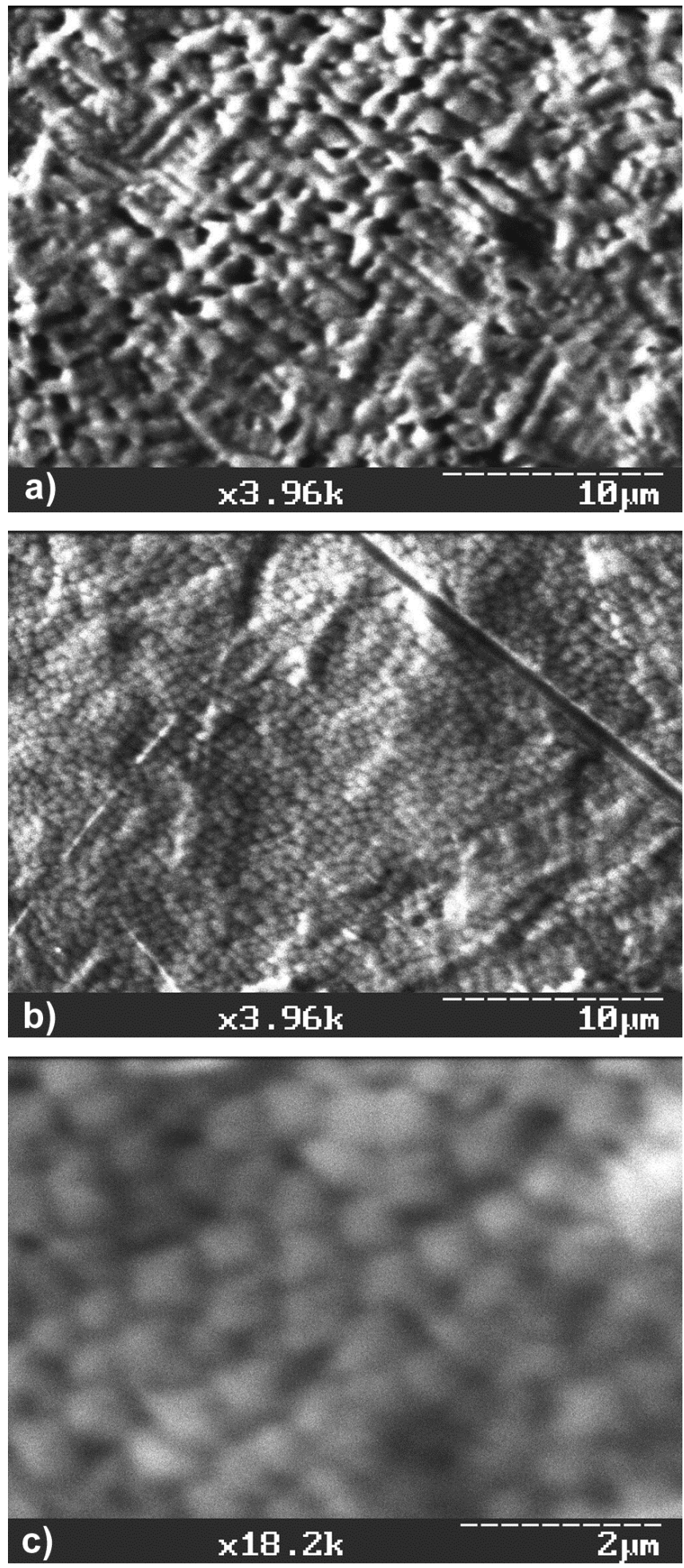

Fig. (5). SEM of the surface of a structural steel specimen after plasma-detonation treatment: (a) - 5 pulses; (b, c) - 10 pulses.

Fig. (7) shows loading diagrams for the surface layer of steel U8 (C-0.8\%), before and after the pulsed-plasma treatment.

Contact in both cases was purely of an elastic character, but it differed in the value of displacement of the indenter (2.5 times) under the identical load. Nano-hardness tests 


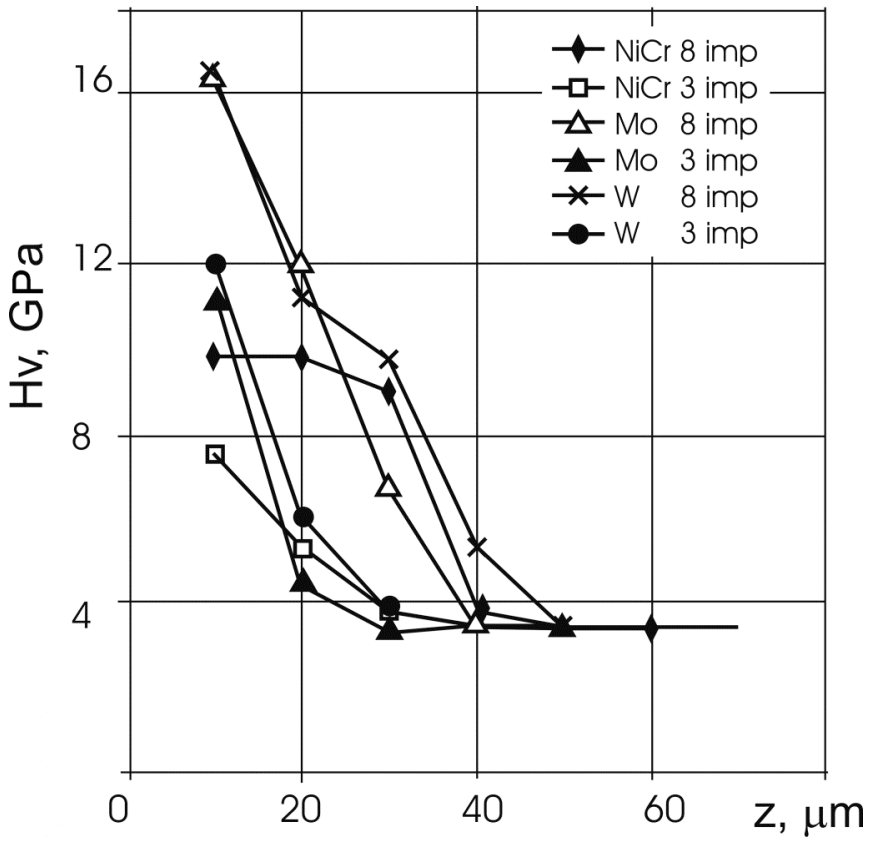

Fig. (6). Variations in hardness of the hardened layer depending upon the quantity of plasma pulses.

were performed using the Berkovich trihedral indenter under low (0.001-15 g) loads. Dependence of the Berkovich indenter upon the load was fixed with a high accuracy during the tests. Elasticity modulus of the modified layer on the surface of steel can be estimated from the loading curve. The hardness value also averages $16 \mathrm{GPa}$.

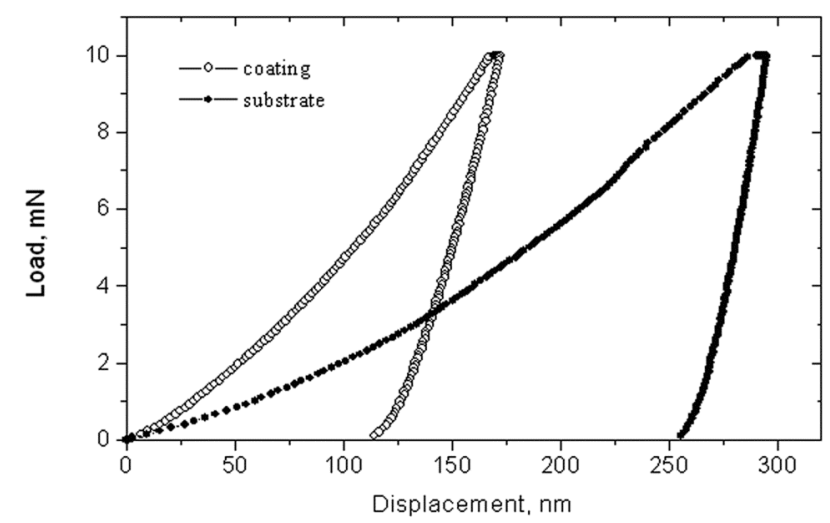

Fig. (7). Diagram of loading depending upon the displacement of indenter for a coating layer ---o--- produced by plasma-detonation treatment and quenched steel U8 $(0.8 \% \mathrm{C})$.

X-Ray phase analysis of a metal alloy hardened by the pulsed plasma fixes broadening of the $\alpha$-Fe lines and emergence of the Fe retained austenite lines [11]. Increase in the number of pulses causes further broadening of the $\alpha$-Fe lines with decrease in their intensity, as well as increase in the relative intensity of the $\gamma$-Fe lines. The amount of austenite under the same treatment conditions is maximal in the case of using a tungsten electrode. X-Ray spectral analysis showed that the consumable electrode material penetrates into the hardened layer of a work piece. For example, in the case of treatment of the surface with a specific power of plasma equal to $10^{6} \mathrm{~W} \mathrm{~cm}^{-2}$ and adding tungsten into the plasma, it was detected in the hardened layer at a depth of down to $20 \mu \mathrm{m}$ [12]. As shown by the investigations, after affecting the workpiece surface by the nitrogen-containing plasma pulses, the concentration of nitrogen at a depth of 20 $\mu \mathrm{m}$ increased to 3.2 at. \% (Fig. 8).

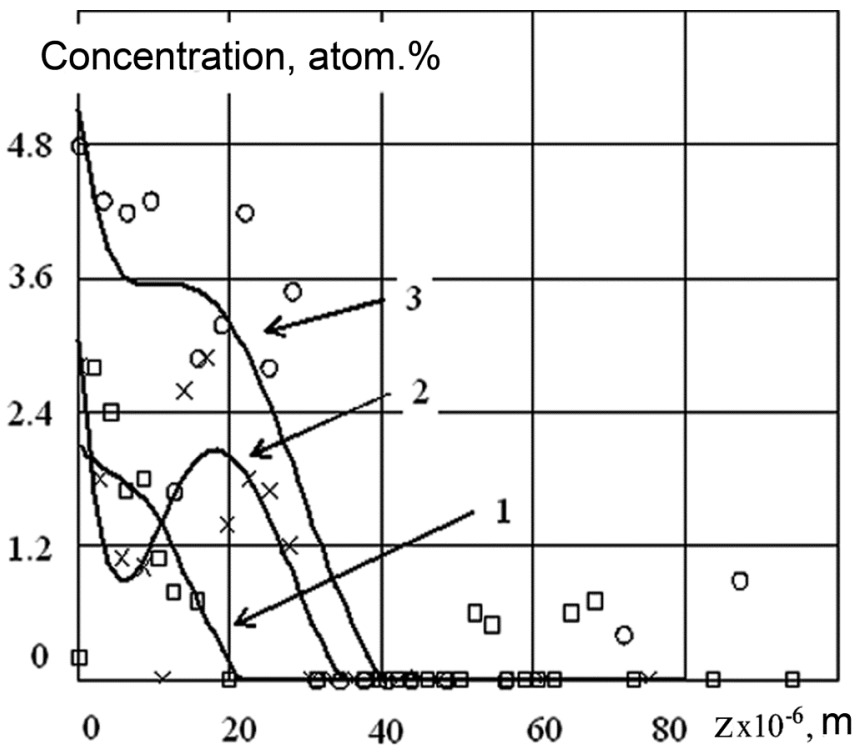

Fig. (8). Variations in the concentration of nitrogen in carbon steel depending upon the quantity of treatment pulses: $\mathbf{1}-10$ pulses; 2 20 pulses; $3-30$ pulses.

Estimation of the value of mass transfer of light elements was conducted by the Auger-spectroscopy methods. The quantity of the plasma pulses affecting the specimen surface was varied during the treatment (in a range of 10 to 30 pulses). Distribution of the concentration of elements through thickness of the layer was studied using the LAS2000 unit on skew sections at an angle of $8^{\circ}$ to the surface. As shown by the studies, during the pulsed-plasma treatment process the coefficients of mass transfer of light elements $(\mathrm{N}, \mathrm{O}, \mathrm{C})$ amount to $\mathrm{K}=10^{-4}-10^{-5} \mathrm{~cm}^{2} \mathrm{~s}^{-1}$, which is higher than the coefficients of thermal diffusion $\left(D=1.5 \cdot 10^{-6}\right.$ for nitrogen at $\mathrm{T}=1000^{\circ} \mathrm{C}$ ).

Structure of the treated layer is sub-microcrystalline, and is characterised by the presence of globules of the electrode material. For example, after three treatment pulses the content of molybdenum at a depth of $10 \mu \mathrm{m}$ was 8 at \% (Fig. 9).

Concentration, atom. \%

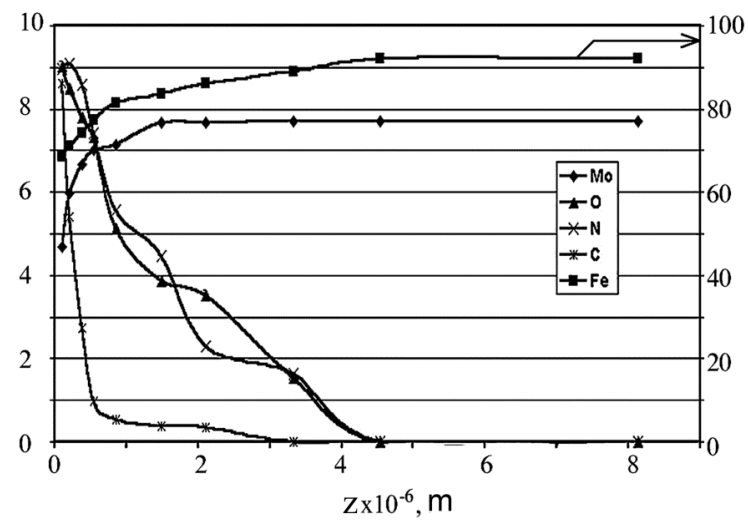

Fig. (9). Distribution of alloying elements $\mathrm{Mo}, \mathrm{O}, \mathrm{C}$ and $\mathrm{N}$ in surface layer of martensitic steel. 
One of the variants of pulsed-plasma treatment is super rapid cooling of the work piece surface alloyed in the melt. Blurring of the cluster boundaries, as well as their "freezing" through overcooling, leads to formation of meta-stable structures characterised by very intensive fragmentation of structural elements. This is demonstrated by the kind of structure of the modified layer revealed by transmission electron microscopy (Fig. 10) [11].

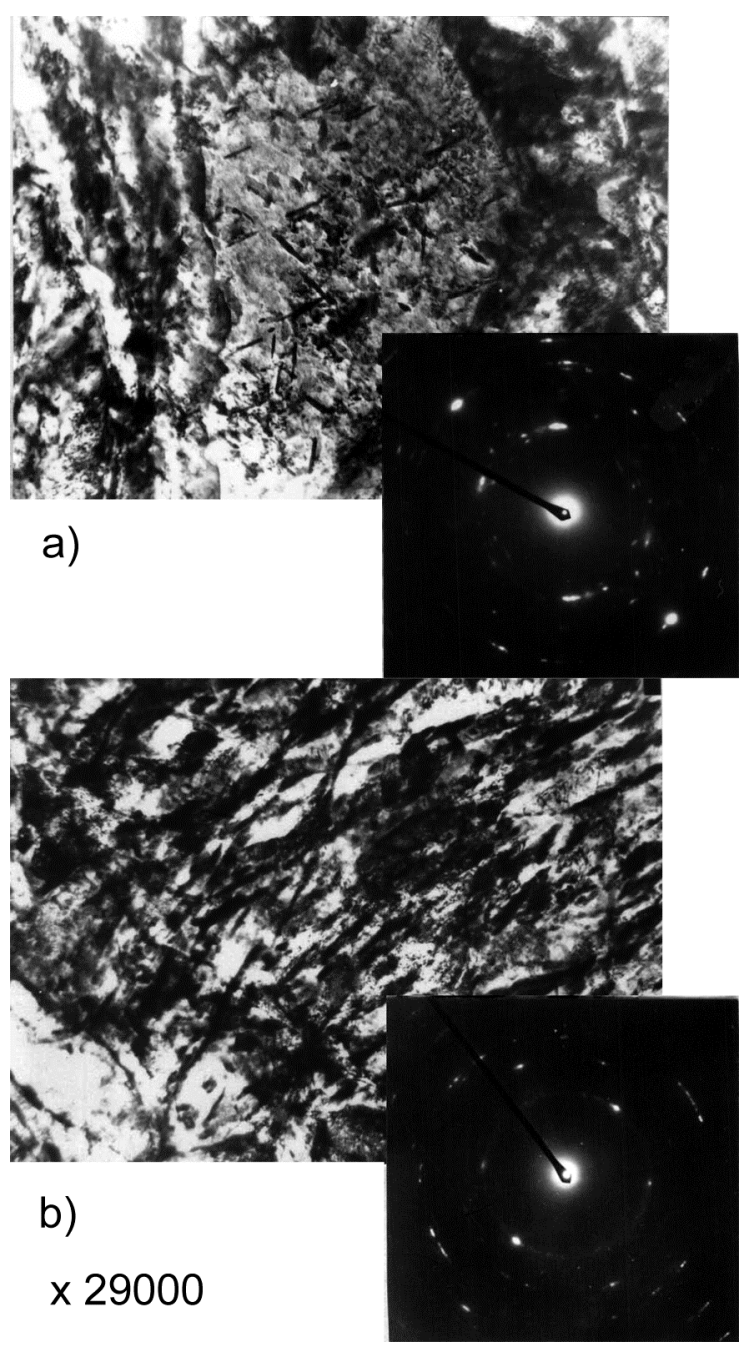

Fig. (10). Structure of layer in alloy $(0.4 \% \mathrm{C}, 1 \% \mathrm{Cr})$ revealed by TEM: (a) initial state; (b) after plasma-detonation treatment.

Emergence of an almost continuous thin ring corresponding to reflexes (110) of $\alpha-\mathrm{Fe}$ in the electron diffraction pattern is indicative of an additional fragmentation of structure after the plasma treatment.

It can be seen on the photo of fracture (Fig. 11a) that the structured layer fractured as a monolith without cracks and distortions. Fracture of the base metal has the form of coarse elongated grains with slip traces and boundary cracks.

$\mathrm{X}$-Ray phase analysis reveals a high intensity of the austenite lines in the coating layer, which grows with intensification of treatment. This is caused by development of crystallographic texture in phase recrystallisation of an alloy under the cooling conditions at the presence of a high temperature gradient. It is a known fact that the preferential orientation along the temperature gradient, i.e. direction $<001>$, takes place under the above conditions for crystalline materi- als with the cubic lattice, which shows up in a relative growth of the intensity of line (200). Examination of broadening of X-Ray diffraction lines shows that after the plasma treatment the broadening of both $\alpha$-Fe and $\gamma$-Fe lines can be considered proportional to $\operatorname{tg} \mathrm{Q}$, which is indicative of a predominant contribution to broadening by heterogeneous elastic distortions of the lattice [10-12]. These distortions may be related to elastic strains caused by dislocations and/or coherent bonds of particles of different phases.
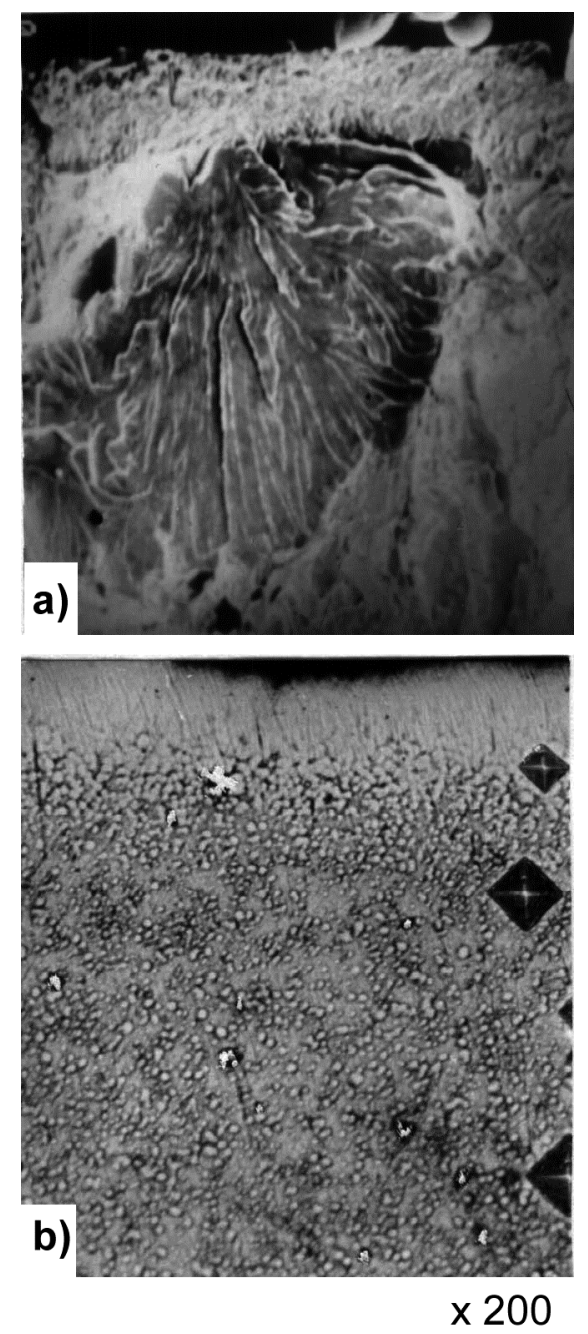

Fig. (11). Types of fracture (a) and cross section (b) of layer produced by plasma-detonation treatment on the surface of steel specimen.

\section{CONCLUSIONS}

The efficient plasma-detonation device (PDD) is offered to provide an integrated impact on the surface being modified by the electric, magnetic, thermal, mechanical, acoustic pulses. Pulsed plasma jets generated by PDD have power density of $10^{3}$ to $10^{7} \mathrm{~W} \mathrm{~cm}^{-2}$, temperature of $4 \cdot 10^{3}$ to $20 \cdot 10^{4}$ $\mathrm{K}$, and velocity of 2000 to $8000 \mathrm{~m} / \mathrm{s}$.

Surface treatment is accompanied by a set of effects providing accelerated transfer of alloying elements in the liquid and solid phases, and crystallisation with formation of a submicrocrystalline layer up to $60 \mu \mathrm{m}$ thick. This layer contains alloying elements, which are introduced into the plasma jet. 
The plasma-detonation technology allows formation of a modified coating layer on the working surface of parts. Combination and quantity of alloying elements introduced into plasma are selected on the basis of application of a part and type of a metal alloy. Alloying elements can be introduced to the plasma in the form of products of erosion of a special electrode, in the form of gas (propane, nitrogen), and in the form of a powder.

Addition of vapour-droplet Mo phase (from the fractured electrode) to the plasma leads to a change in phase composition of the surface layer and formation of intermetallic compounds $\mathrm{Fe}_{7} \mathrm{Mo}_{6}$ and FeMo. Treatment of the coating surface by the pulsed plasma jet provides formation of intermetallic compounds, and melting with the electron beam provides mixing of the coating and substrate components.

The plasma-detonation technology allows a short-time heating of the surface layer $(20-40 \mu \mathrm{m})$ up to its melting. Introduction of metals into the molten layer and simultaneous effect by a combination of physical fields provide stirring and formation of new alloys containing intermetallic compounds.

The time of interaction of the metal-containing plasma with the work piece surface is no longer that $10^{-3} \mathrm{~s}$, which allows the surface of parts to be modified without heating. The technology offered provides formation on the work piece surface of a thin layer, which contains different alloying elements, such as nitrogen, carbon and metals. Crystallisation of the layer of the melt on the work piece surface takes place in a set of different physical fields (acoustic, electromagnetic) at high temperature gradients, which provides formation of its dispersed crystalline state.

The layers formed on the surface are characterised by high hardness and adhesion to the work piece surface. This allows the plasma-detonation technology to be recommended to harden surfaces of heavy-loaded parts without their heating and loss in strength.

Experience of commercial application of the technology showed that performance, e.g. of metal-working tools at steel-rolling mills, increases 3-6 times after the plasmadetonation treatment [13].

\section{ACKNOWLEDGEMENT}

The authors express their sincere gratitude to Prof. Pogrebnyak A.D., Prof. Dub S.N and Prof. Perekrestov V.I. for their direct assistance in conducting the investigations.

\section{REFERENCES}

[1] Todaka Y, Umemoto M, Liand J. Nanocrystallization of carbon steels by shot peening and drilling. Rev Adv Mater Sci 2005; 10: 409-8.

[2] Rott M, Raif M, Igenbergs E. Surface modification processes by hypervelocity plasma pulses. Int J Impact Eng 2006; 33: 691-702.

[3] Shmelev V, Podoynitsyn S, Vasilik N. Application of the ballistic plasmatron of superadiabatic compression for surface treatment. Surf Coat Technol 2006; 200: 4939-8.

[4] Uglov V, Anishchik V, Astashynski V. Structure and phase transformation of iron surface layer treated by compression nitrogen plasma flows. Surf Coat Technol 2004; 180: 633-4.

[5] Al-Tibbi V, Kabirov Yu, Dymochkin DM. About nanodimension effect at hardening of friction surfaces by a method of electroacoustic spraying. Electron J (Investigated in Russia) 2005; 8: 1509. Available at: http://zhurnal.ape.relarn.ru/articles/2005/015.pdf

[6] Tobar M, Alvarez C, Amado J. Laser transformation hardening of a tool steel: Simulation-based parameter optimization and experimental results. Surf Coat Technol 2006; 200: 6362-6.

[7] Abboud J, Benyounis K, Olabi A. Laser surface treatments of ironbased substrates for automotive application. J Mater Process Technol 2007; 182: 427-5.

[8] Promtov M. Machines and devices with pulse power influence on processable substances. Mashonostroyeniye-1: Publ. House Moscow 2004.

[9] Tyurin Y. Pogrebnjak A. Advances in the development of detonation technologies and equipment for coating deposition. Surf Coat Technol 1999; 111: 269-7.

[10] Pogrebnjak A, Tyurin Y. Hardening and mass transfer at pulse plasma-detonation processing of steel. Phys Chem Mater Process 2002; 2: 40-9.

[11] Losko D, Milman Yu, Yefimov N, Korzhova N, Tyurin Yu. The physical nature of hardening of steel U8 by plasma-detonation working. Ukranian Phys J 1999; 6: 764-8.

[12] Pogrebnjak A, Tyurin Yu. Modification of material properties and coating deposition using plasma jet. Successes Phys Sci 2005; 48 : 487-16.

[13] Tyurin Y, Kolisnichenko O, Tsygankov N. Pulse-plasma hardening of tools. Autowelding 2001; 1: 13-6.

This is an open access article licensed under the terms of the Creative Commons Attribution Non-Commercial License (http://creativecommons.org/licenses/by$\mathrm{nc} / 3.0 /$ ) which permits unrestricted, non-commercial use, distribution and reproduction in any medium, provided the work is properly cited. 